\title{
Early Chronology of Sumer and Egypt.
}

O N Wednesday, April 27, Prof. S. Langdon delivered a lecture on behalf of the Egypt Exploration Society at the Royal Society's rooms at Burlington House on "The Early. Chronology of Sumer and Egypt and the Similarities of their Culture." The chair was taken by Lord Carnarvon, who has just returned from Egypt and gave a few interesting details of recent excavation work carried out there.

Prof. Langdon said that the ancient people commonly known as the Egyptians were not the first civilised people on the banks of the Nile, but they were preceded by an Asiatic people who were probably Sumerians or Elamites. These two Asiatic peoples are now known to have belonged to the same race, and they founded the first organised societies known to history on the shores of the Persian Gulf and in Elam in the Stone age. The Sumerians, the most, talented branch of a widely spread race, spoke a highly organised agglutinating speech. They are found in prehistoric levels from the head of the Persian Gulf northwards along the banks of the Euphrates and the Tigris as far as Assur, north of the Lower $\mathrm{Zab}$, and in Russian Turkestan. Recently discovered dynastic tablets establish the date of the earliest kingdoms of Mesopotamia as early as 5000 B.c. At that time the Semites had already invaded the Mesopotamian Valley and established themselves in the region of Bagdad. The history of ancient Babylonia consists of two rival kingdoms, Sumer in the south, the principal capital of which was Erech, and Kish in the north, the principal capital of which from 5000-2900 B.C. was at Kish.

The earliest Sumerian culture is strikingly similar to that of prehistoric Egypt; it must be assumed that a branch of this people occupied Upper Egypt in the region of Abydos and Hieraconpolis as early as 5000 B.c. The Sumerian linear pictographic writing is clearly revealed in the Egyptian pottery markings which preceded the Egyptian hieroglyphs. This writing is known to have been well developed in Sumer or ancient Chaldea before 3800 B.c., and the prehistoric Egyptian linear style cannot be much later. The Sumerians and Elamites appear to have reached Egypt by sea routes, trading and adventuring along the coasts of southern Arabia until they reached Punt, Ethiopia, and finally the Nile Valley in the region of Coptos. All their prehistoric remains have been found in Upper Egypt, principally at Abydos and Naghada. They brought with them into Egypt the cylinder seal, the mace head, and a style of decoration in stone which is characteristic of Sumerian art.

The characteristic features of this remarkable people were a long head of large brain capacity, a thin, high nose which joined the cranium without depression, a slightly receding forehead, and eyes the axes of which are not horizontal, but slant slightly outward. The position of the axis of the eye is precisely the reverse of the Mongolian type. It is possible to discern in their prehistoric tomb paintings in Egypt the same physical characteristics. They disappeared in Egypt some time before the first Egyptian dynasty founded by Menes, and were superseded by an African people who amalgamated with Semitic races from Asia. This new race invented their own system of writing, which developed into the classical hieroglyph. The older Sumerian linear style appears to have been used in Egypt without intelligence even by the SumerianEgyptians themselves. It was probably never understood in Egypt, and the signs survived only as occult marks on pottery after the older Asiatic peoples had disappeared.

The religion of the Egyptians is obviously related to the Sumerian, and there is no Semitic influence in the fundamental religious concepts of the ancient religions of Babylonia and Egypt. The names of the gods in both pantheons do not reveal a single Semitic name. It is probable that the great cults of Tammuz and Osiris are the creations of two branches of the same people, that of Osiris being inherited by the Egyptians from the older Asiatic people.

Prof. Langdon attempted to fix the beginning of the first Egyptian dynasty by comparing the methods of year-dating of the famous Semitic Emperor Naram. $\sin \left(2795^{-39}\right.$ B.c.) with those of Egypt. He argued that Naräm-sin borrowed his system of year-dating from Egypt, and showed that this could have taken place only after Den, fifth king of the first dynasty. He also argued from archæology to make Narām-sin a contemporary of the last two kings of the second Egyptian dynasty. He arrived by these two methods at a date circa 3200 B.c. for Menes.

\section{Imperial Forestry Education.}

THE Report of the Interdepartmental Committee on Imperial Forestry Education appointed to prepare a scheme for giving effect to the resolutions of the British Empire Forestry Conference of 1920 with regard to a central institution for training forest officers has just been issued (Cmd. rr66, H.M. Stationery Office, $2 d$.). Keeping in view the decision of the conference that the future higher training in forestry should take place at a single central institution, the Committee recognises that the main object to be aimed at in the training of forest officers is to turn out men fully equipped with theoretical and practical knowledge, with minds broadened br education, and with capacity, strengthened by practical experience in forest work, to direct men and operations. It considers that it would be a retrograde course to interfere with the work already done by universities in establishing and maintaining courses of training in forestry, and seeks rather to co-ordinate all these courses, to bring them up to a common level, and to utilise them as a preliminary to a higher course of training at one centre.

NO. 2688, VOL. IO7] .
Under this scheme the course of study at a university would extend over three years, leading to a degree in forestry; at this stage men would be selected as probationers for one or other of the forest services, and admitted to the central institution for a period of higher training extending over one year in the case of ordinary forest officers, or longer in the case of those who propose to specialise. In order to widen the field for recruitment and to obtain men with a high scientific training, it is considered desirable that a certain number of probationers should be selected with honours degrees in science; these men should then, after a forestry course covering the second and third years at a university school, spend a final year at the central institution. In the case of men required as specialists honours graduates in science should be selected, given such a course in general forestry as may be considered necessary, and then sent for two years to the central institution.

The Committee directs attention to the great value of maintaining close relations between the central training institution and research work; research into 
questions affecting forest production as well as entomology, mycology, soil science, and the like should form part of the work of the central institution.

It is proposed that the central institution should be located at Oxford, incorporated with the University, and governed by a board appointed one half by the Departments or Governments concerned and the other half by the University. The director (who should be the professor of forestry) and the staff should be appointed by the University with the approval of the board. The Departments concerned should jointly guarantee to the board an annual sum sufficient to pay the costs of the institution, and should defray any deficit in the annual working in proportion to the number of students trained for the services of each Department. It is estimated that the annual cost of the permanent staff should not at the commencement exceed 40ool. per annum. No estimate of the capital cost of the proposed scheme can be made until detailed plans of such buildings as the University are prepared to provide have been obtained and discussed, but pending the erection of permanent buildings it has been ascertained that arrangements can be made with the University for temporary accommodation.

Among other proposals is one that officers of every forest service should at one period of their career return to the institution for a special course.

\section{University and Educational Intelligence.}

Cambridge.-Dr. J. H. D. Scott and Mr. W. W. Harvey, of Christ's College, have been elected to John Lucas. Walker studentships in pathology.

Mr. T. C. Wyatt has been elected to a fellowship at Christ's College.

The directors of Messrs. Barclays Bank, Ltd., have given roool. towards the cost of the new engineering laboratory.

Details of the latest proposals as to women students at Cambridge have now been published. The memorial (which has been signed by nearly two hundred residents, including Sir Clifford Allbutt, Prof. Eddington, Dr. Fenton, Dr. E. H. Griffiths, Prof. Inglis, Sir William Pope, Dr. Rivers, Prof. Seward, Sir Joseph Thomson, and Dr. Whetham) asks that women shall be matriculated as members of women's colleges; shall be eligible for all degrees with all privileges except membership of the Senate and of the Electoral Roll; also that they shall be eligible for scholarships, prizes and studentships, professorships, readerships, lectureships, and examinerships of the University and for membership of boards and syndicates. Women would be present on the council of the Senate as assessors without vote. There would be provision against mixed colleges and against an increase of resident women in statu pupillari beyond 500. The council proposes to have this scheme and the alternative scheme, which merely. olfers the women titular degrees, voted on during the present term. The new scheme is the result of a conference between some of the supporters and some of the opponents of the old Report A, and is backed by the signatures of ${ }_{1}{ }_{5}$ supporters of Report A and of $5^{\circ}$ opponents of this report.

LoNDON.-The first of a course of eight advanced lectures in physiology was given in the physiological laboratorv, St. Bartholomew's Hospital, West Smithfield, E.C.I, on Tuesday, by Prof. W. D. Halliburton upon the subject of Cerebro-spinal Fluid. The remaining lectures will be as follows :-May ro, Prof: NO. 2688 , VOL. IO7]
M. S. Pembrey, The Secretion of Milk; May I7, Mr. J. Barcroft, Alpinism; May 24, Prof. W. M. Bayliss, The Reaction of the Blood; May 3x, Prof. J. B. Leathes, Tyrosine; June 7, Prof. E. H. Starling, The Heart in Exercise; June I4, Dr. H. H. Dale, Anaphylaxis; and June 21, Dr. Leonard Hill, The Capil. lary Circulation.

'Another course of eight lectures on "Reception of Sensory Stimuli" will be given by Prof. H. E. Roaf in the physiology theatre, London Hospital Medical College, Turner Street, Mile End, E.1, at 4.30 p.m., on Thursdays, May I2, I9, and 26 and June 2, 9, I6, 23, and 30. The lectures in each course are addressed to advanced students of the University and to others interested in the subject. Admission is free, without ticket.

The Zionist Organisation is prepared to send a lecturer on the Jewish national movement free of all charge to any organisation or society. The lecture can be illustrated by lantern-slides dealing with Pales. tinian life and scenery. Persons interested should write to the Lecture-Secretary, Zionist Organisation, 77 Great Russell Street, London, W.C.I.

A provisional programme has been issued of the summer meeting of the Institution of Electrical Engineers to be held at the Scottish centre (Glasgow) on June 7 -Io. On the first day of the meeting Mr. R. B. Mitchell will describe the Dalmarnock generating station, which will be followed by a visit to this power station. On the second day Prof. M. Maclean will give a paper entitled."The Hydro-electric Resources of the Scottish Highlands." The last dav of the meeting will be spent 'at Oban, and a visit will be paid to the hydro-electric installation of the British Aluminium Co.

Acting in co-operation with the Royal Academy of Sciences in Holland, the Anglo-Batavian Society is attempting to foster a fuller understanding between scientific men in Holland and England by arranging for addresses to be given by Dutch lecturers in London and by English men of science in the four universities of the Netherlands. In March last the lectures in Holland were inaugurated at Leyden by Dr. Thomas Lewis, of University College Hospital, who gave an account of his recent work on the heart. On April 14 and 16 Prof. Elliot Smith delivered addresses at Groningen and Utrecht respectively on "Vision and Evolution." In rg12 Prof. Elliot Smith directed attention (Nature, September 26, I9I2) to the far-reaching results in the evolution of the Primates of the substitution of vision for smell as the guiding sense in man's arboreal ancestors. In the Montgomery lecture in Dublin last autumn he developed this theme further by demonstrating the profound influence exerted upon the evolution of the brain by the acquisition of stereoscopic vision. In the lectures given in Holland attention was concentrated on the changes which are brought about in the cerebral cortex of an animal which for the first time acquired powers of true observation and the means of appreciating form, space, and time. The possession of acute vision in conjunction with extreme mobility and co-ordination of the eyes and such delicate tactile instruments as the hands, which under the guidance of vision explore the surrounding world and learn by experiment, gave the animal the curiosity and the incentive to embark. upon the voyage of discovery which eventually led to the emergence of man's intelligence and æesthetic appreciation, and as a result the attainment of his distinctive knowledge and powers of discrimination. 